\title{
Why is short-term sentence recall verbatim? An evaluation of the role of lexical priming
}

\author{
MING-WEI LEE \\ University of Cambridge, Cambridge, England \\ and University of Wales Bangor, Bangor, Wales \\ and \\ JOHN N. WILLIAMS \\ University of Cambridge, Cambridge, England
}

\begin{abstract}
By showing that short-term sentence recall can be significantly affected by words encountered in an intervening distractor task, Potter and Lombardi (1990, Joumal of Memory and Language, 29, 633-654) argue that short-term sentence recall is often verbatim because of the availability of recently activated lexical entries during the regeneration of the sentence from its conceptual representation. We show that similar effects can be obtained even when bilinguals perform an intervening task in a different language from that of sentence recall, or when monolinguals perform an intervening task upon pictures. Furthermore, we show that the presentation of a word in P\&L's distractor task does not, in any case, affect subsequent retrieval of a semantically related word as measured in a picture-naming task. We suggest that the effects on recall reported here and by P\&L should be explained in terms of conceptual level interference at the time of recall. We also discuss the implications of our suggestion for the issue of the verbatimness of short-term sentence recall.
\end{abstract}

Short-term sentence recall is traditionally regarded as involving a process of "reading off" the short-lasting representation(s) of the surface form of information of a sentence-for example, the phonological, orthographic, auditory, or articulatory representations (see, e.g., Glanzer, Fischer, \& Dorfman, 1984). Potter and Lombardi (1990; hereafter $P \& L$ ) mount a challenge to this view and argue instead that like long-term sentence recall, short-term sentence recall involves a process of regenerating a sentence from its conceptual representation using the normal mechanisms of sentence production. They hypothesize that the accuracy and verbatimness of short-term recall compared with long-term recall is due to the fact that in the former case the regenerative process is aided by the added availability of a set of unordered recently activated lexical entries in the mental lexicon (we shall refer to this as the lexical priming account). In the present article, we do not contest $\mathrm{P} \&$ L's view that short-term sentence recall involves a process of regeneration from the conceptual level (although we suspect that regeneration is probably not the

The work reported on in this article was conducted while the first author was in receipt of an Overseas Research Student Award from the Committee of Vice-Chancellors and Principals of the Universities of the United Kingdom, a bursary from the Cambridge Commonwealth Trust, and a sponsorship from the University of Cambridge Local Examinations Syndicate. We thank Stephen Monsell and Linda Wheeldon for supplying the computerized pictures used in Experiments 2 and 3 and the similarity ratings used in Experiment 3 . We are also grateful to Mary C. Potter and three anonymous reviewers for their comments on earlier versions of this article. Correspondence should be sent to $\mathbf{J}$. N. Williams, Research Centre for English and Applied Linguistics, University of Cambridge, Keynes House, Trumpington Street, Cambridge CB2 1QA, England (e-mail: jnw12@cus.cam.ac.uk). only process). Our primary purpose is to critically examine the role of lexical priming in short-term sentence recall.

P\&L developed a novel experimental paradigm, the results from which, they claim, support not only their regeneration hypothesis, but also their lexical priming hypothesis. We take as the basic paradigm the one used in Experiments 1, 3, and 6 of P\&L and in parts of Experiments 1 and 2 of Lombardi and Potter (1992); it can be analyzed as follows: (1) Subjects read a to-be-recalled sentence presented under rapid serial visual presentation (RSVP); (2) shortly after the offset of the last word of the sentence, subjects are presented with a list of five unrelated words, again under RSVP, after which a further word appears and subjects have to indicate whether it occurred in the list of five words (this, or its variants, will be referred to as the distractor task); (3) subjects recall the sentence aloud. On some of the trials, one of the words in the list is approximately synonymous with one of the words in the sentence. For example, the sentence The knight rode around the palace searching for a place to enter might be followed by the word list turtle, recipe, booth, castle, medal, where castle is assumed to be approximately synonymous with palace, at least in the context of the sentence (indeed, the word in the list was selected so as to be, if anything, preferable in the original sentence). The word in the sentence will be referred to as the target, and the approximate synonym in the list, the lure (the probe for the distractor task was never the lure). What is of interest is whether subjects will inadvertently recall the sentence with the target word replaced by the lure, despite instructions to recall the sentence as accurately as possible. And 
indeed, P\&L found that while the rest of the sentence was almost always recalled verbatim, subjects were more likely to replace the target with the lure (recalling the sentence as The knight rode around the castle searching for a place to enter) when the lure was present in the word list than when it was not (the latter cases will be referred to as spontaneous intrusions, and presumably reflect the naturalness of the lure word in the sentence context). This basic phenomenon will be referred to here as the lure intrusion effect.

The essential paradox presented by P\&L's results is that while sentence recall is almost always verbatim, subjects still have a tendency to recall a sentence with the target word replaced by the lure. If the verbatimness of sentence recall in this experiment simply reflected output from short-term surface memory, this should not happen (unless the target and lure were phonologically and/or orthographically confusable, which they were not). P\&L therefore propose that short-term sentence recall in these experiments was not achieved by reading out from shortterm surface memory, but rather the subjects simply recalled a conceptual representation of the sentence and expressed this by using the normal mechanisms of language production, which include lexical access, syntactic encoding, phonological retrieval, and articulatory planning and execution (see, e.g., Levelt, 1989), a process that is no different in kind from that which is commonly supposed to support characteristically nonverbatim recall from longterm memory.

Why, then, on this view, is short-term sentence recall verbatim, and how can the lure intrusion effect be accounted for? P\&L believe that the lexical access component in sentence production holds the key to both of these phenomena and explain them by appealing to what they refer to as "lexical priming" in the mental lexicon. ${ }^{1}$ A lexical entry is regarded as partly composed of an evidenceaccumulating device which becomes active to the extent that its conditions are met by the currently active concepts (this view is suggested by their equating lexical entries with logogens, p. 635). "Priming" of a lexical entry can be regarded as an increase in its level of activation, resulting, in P\&L's experiments, from the presentation of the word either in a recently read sentence or in the wordmatching task. This gives that entry an advantage in the subsequent competition with other entries for selection for use in expressing the conceptual content of the to-berecalled sentence. The result is that most of the conceptual content of the sentence meaning happens to be expressed using the same words as the original, with the exception of the concept originally referred to by the target word, which now is sometimes expressed using the lure word. The nonverbatimness of long-term sentence recall would occur because the effect of lexical priming has dissipated by the time recall occurs (although $P \& L$ have no evidence concerning how long lexical priming persists). Note that in order for this account of the lure intrusion effect to work, it needs to be assumed that the lure word provides as good a way of expressing the relevant concept as does the target word, at least in the context of the sentence (and given whatever vagueness might be present in the conceptual representation at the moment of recall).

We regard P\&L's theory as an interesting attempt to explore the interface between verbal learning and memory research and psycholinguistics research; it explains the lure intrusion effect, and ultimately, the verbatimness of short-term sentence recall, a classic explanandum in memory research, in terms of a relatively well-studied psycholinguistic process- -namely, the lexical access process in sentence production (see review by Bock \& Levelt, 1994). It is an illustration of what Jakimik and Glenberg (1990) have called the "mutual contributions" (p. 588) that memory research and psycholinguistics research may have for each other. We reasoned that an obvious implication of $P \&$ L's theory of short-term sentence recall for research methodology in experimental psycholinguistics was that the lure intrusion effect could be used to study the lexical access process in sentence production, thereby freeing experimental psycholinguists from their reliance on the picture naming task as a tool for the study of the lexical access process in language production.

Assuming P\&L's lexical priming account of the lure intrusion effect to be correct, we originally intended to use the first experiment reported here to study a question in psycholinguistics: namely, the issue in bilingual language processing of whether for some (fairly proficient but far from balanced) bilinguals, the lexical representations of translation equivalents are highly interconnected (see, e.g., Chen \& Leung, 1989; de Groot \& Nas, 1991; Kroll \& Stewart, 1994). If this should be the case, then, in P\&L's paradigm, presenting the lure in a different language from the sentence would not eliminate the lure intrusion effect. That is, when a person who knows both French and English is given a sentence to read in English (e.g., The autumn evening was chilly so the man put on his jacket before leaving for the concert), followed by a word-matching task in French (containing, e.g., the lure manteau, meaning "coat" in English), followed by sentence recall in English, then a French "lure" word in the word-matching task should appear in its English translation in that person's recall of the original sentence (e.g., The autumn evening was chilly so the man put on his coat before leaving for the concert). Such a phenomenon would suggest that the representation that is primed by the French lure is not language specific but still lexical (and nonconceptual).

In the event, the preceding predictions were borne out. Indeed, the cross-language lure intrusion effect was nearly as large as the within-language effect (see Experiment 1, below). However, in the course of running the experiment, we began to suspect that there was an alternative explanation of the lure intrusion effect that was not dependent on lexical priming at all, and which would be indifferent to the form of the lure event. This was that lure intrusions were due to a change in the memory for the original sentence at the conceptual level, a phenomenon that we shall refer to as conceptual distortion (the processes that might be responsible for this will be considered in the General Discussion). Experiment 2 was designed as a further test of this idea, and in Experiment 3 we examined whether 
lexical priming could, even in principle, account for the lure intrusion effect in P\&L's paradigm.

Whether the lure intrusion effect is explained in terms of conceptual distortion or lexical priming is probably not in itself of great significance (although it is necessary to clarify the theoretical basis on which the shortterm sentence recall task can be employed as a tool in studies of language production; see, e.g., MacDonald, Bock, \& Kelly, 1993). What is important is that if the lure intrusion effect is not due to lexical priming, then a lexical priming account of verbatimness in short-term recall becomes untenable, because just as the lure is supposed to bias the lexicalization process in its favor and away from the target, priming from the words of a sentence is supposed to bias the lexicalization process in their favor and away from any lexical competitors under normal circumstances. But at the same time, the lure intrusion effect, even if explained in terms of conceptual distortion, seems to demand that short-term recall be regeneration from the conceptual level, and not the simple product of reading out a form-level representation from short-term surface memory. The question of why short-term memory for sentences in P\&L's paradigm is verbatim, then, is still rather puzzling because regeneration from the conceptual level (as in long-term recall) is characteristically not verbatim. We return to this issue in the General Discussion.

\section{EXPERIMENT 1}

In Experiment 1, on each trial subjects read a to-berecalled sentence in English, performed the distractor task (the word-matching task) in either English or French and then recalled the sentence aloud in English. Every parameter of $P \& L$ 's basic paradigm was maintained, except that the five unrelated words were presented half as quickly for subjects who performed the distractor task in French. This was because French was the second language of the subjects, and it was obvious that French words would not be processed to the same extent as English words if they were presented at the same rate. This difference in presentation rate in the distractor task amounts to a difference in the time lag between sentence presentation and recall, but whether it would create an insurmountable comparability problem can be gauged, we suggest, from the rate of overall recall of the sentences and from the spontaneous intrusion rate, against which the lure intrusion effect would be measured. We submit that as long as the subjects who performed the distractor task in French showed a comparably high level of performance in recall, there was no reason not to believe that it was short-term sentence memory which was being tapped in these subjects. It should also be noted that since for P\&L there is little distinction, apart from the alleged difference in lingering lexical activation, between the regenerative processes involved in short- and long-term sentence recall, any slight increase in lag between sentence presentation and recall is of little significant consequence-no influence of French lures should be obtained, no matter what the lag is.

\section{Method}

Subjects. The 24 subjects were undergraduates who had volunteered and were paid to participate. At the time of testing, 12 of them had studied French for at least 6 years $(M=8.9$ years, $S D=$ 1.97 years), had traveled extensively and/or lived in France and/or other French-speaking countries in Europe, and were studying French language and/or literature as their main subject in the university. They scored a mean of 2.83 (out of 4$)(S D=0.39)$ on the adapted version of a published scale for self-ratings of communicative ability in a second language (Bachman \& Palmer, 1989). The other 12 subjects studied a variety of subjects other than French. All were native speakers of English.

Materials. Twenty-two word triplets $\left(E_{t}-E_{1}-F_{1}\right)$ were found which met all the following criteria: (1) An English sentence could be written in such a way that it included a target word $E_{t}$ for which a lure $E_{1}$ could be found so that, following $P \& L$, the replacement of $E_{t}$ by $E_{1}$ in the sentence would not, as judged by the experimenters, significantly change the meaning of the sentence. (2) A French word $F_{1}$ could be found which, as judged by the experimenters, was the most obvious translation equivalent of $E_{1}$ and was almost certain to be known as such by learners of French at the level of proficiency of our subjects. (3) It is often suggested in the bilingual literature that bilinguals process cognates and noncognates differently (see, e.g., Sánchez-Casas, Davis, \& García-Albea, 1992). To avoid getting into this issue, which is not relevant to the present study, only noncognates were used; therefore, $E_{1}$ and $F_{1}$ were noncognates. In addition, for each triplet, a set of five nouns in English and a set of five nouns in French were selected for use in the word-matching distractor task, with the constraint that they should be similar in number of letters to $E_{1}$ and $F_{1}$, respectively, but unrelated in meaning to each other or to words in the sentence. The sentences were 10-17 words in length, with a mean of 12.8 words. (See Appendix A.)

The 22 triplets were divided into two groups of 11. Two English experimental lists were formed by combining the respective sentences and English distractor sets of the triplets of one group with those of the triplets of the other group, counterbalancing for the group which was formed into the lure-present condition (i.e., for each word pair of the group in the lure-present condition, one of the five nouns in its distractor set was replaced with the appropriate $E_{1}$ ). Two French experimental lists were formed by combining the respective (English) sentences and French distractor sets of the triplets of one group with those of the other group, counterbalancing for the group which was formed into the lure-present condition (i.e., for each word pair of the group in the lure-present condition, one of the five nouns in its distractor set was replaced with the appropriate $F_{1}$ ). Half the sentences in each English or French experimental list were paired with distractor sets with $E_{l} s$ or $F_{l} s$ in them, respectively. The lure, when included, was never the last word in a distractor set, and it was never the word probed by the word-matching distractor task.

In addition, there were 15 practice and filler sentences for each of which a set of five English nouns and a set of five French nouns, chosen according to the same criteria as for those of the 22 triplets, were available.

Procedure. As mentioned above, every parameter of P\&L's basic paradigm was maintained, except that the five unrelated words were presented half as quickly for subjects who performed the distractor task in French.

The sentences and distractor sets were presented using RSVP, with each word centered at the same point on the screen. Each trial began when subjects pressed the space bar on the keyboard. Three hash marks appeared for $300 \mathrm{msec}$ at the center of the screen where the subsequent words would appear, followed by a blank screen for $350 \mathrm{msec}$ and then the words of the sentence at a rate of five words per second. Immediately after the offset of the last word of the sentence, a visual mask in the form of a row of three percentage signs appeared for $517 \mathrm{msec}$, followed by the five distractor words presented at a rate of four words per second for English nouns or two 
words per second for French nouns, and then another row of percentage signs for $250 \mathrm{msec}$. Then, the capitalized probe word appeared for $600 \mathrm{msec}$. Subjects had been instructed to press one of two response keys to indicate their judgment of whether the probe word was one of the five distractor words just presented, and then to recall the sentence aloud as accurately as possible when they saw the word RECALL, which appeared immediately after the computer had registered the subjects' response to the probe word. The subjects then pressed the space bar to initiate the following trial.

Before the experiment began, the subjects were given detailed on-screen step-by-step instructions and five practice trials. Every subject received 32 pseudorandomly ordered trials ( 22 experimental and 10 filler trials), which were divided into three blocks separated by two breaks. On 11 of the 32 trials, the English or French lure was included in the distractor set for subjects who performed the distractor task in English or French, respectively, and no more than two such trials appeared in succession. On half (of which 6 were experimental trials where the English or French lure was included in the distractor set) of the 32 trials, the probe word was included in the distractor set, and on the other half, it was not. The whole experimental session was audio recorded.

Design. The 12 subjects who were students of French received the French experimental lists, 6 for each list; the other 12 subjects received the English experimental lists, again 6 for each list. The design was therefore a 2 (presence of [English or French] lure in the distractor set) $\times 2$ (language of the distractor set) $\times 2$ (list assignment) factorial by subjects, with the latter two factors varied between subjects and the first within subjects, and a 2 (presence of lure) $\times$ 2 (language) $\times 2$ (list assignment) factorial by items, with the first two factors varied within items and the third between items. The main dependent variable was the mean percentage of errors of lure $\left(E_{1}\right)$ intrusion in sentence recall.

\section{Results}

Overall recall of the sentences was good: Apart from the target words, $93 \%$ of the words were recalled correctly $(91 \%$ for the French group, $94 \%$ for the English group). Aside from lure intrusions, there were only $7 \%$ errors in recall of the target words $(9 \%$ for the French group, $6 \%$ for the English group). There were also $12 \%$ errors in the distractor task ( $9 \%$ for the French group, $15 \%$ for the English group).

The mean percentage of errors of (English) lure intrusion in the four critical conditions is shown in Table 1. Both the by-subjects and by-items analyses of variance revealed only a main effect of lure presence $\left[F_{1}(1,20)=\right.$ $12.49, M S_{\mathrm{e}}=.01, p<.01 ; F_{2}(1,20)=19.03, M S_{\mathrm{e}}=.02$, $p<.001]$. No main effect of distractor language or interaction was found (all $F \mathrm{~s}<1$ ). Post hoc analyses showed that the lure intrusion effect was significant by subjects and by items for the English group $\left[F_{1}(1,10)=5.91\right.$, $M S_{\mathrm{e}}=.02, p<.04 ; F_{2}(1,20)=13.17, M S_{\mathrm{e}}=.02, p<$

Table 1

Percentage of Errors of Lure Intrusion in Recall of Target Words as a Function of Lure Presence and Language of Distractor Task in Experiment 1

\begin{tabular}{|c|c|c|c|}
\hline \multirow{2}{*}{$\begin{array}{l}\text { Language of the } \\
\text { Distractor Set }\end{array}$} & \multicolumn{2}{|c|}{$\begin{array}{l}\text { Presence of Lure } \\
\text { in the Distractor Set }\end{array}$} & \multirow{2}{*}{$\begin{array}{c}\text { Lure Intrusion Effect } \\
\text { (Present-Absent) }\end{array}$} \\
\hline & Present & Absent & \\
\hline English & 23 & 9 & 14 \\
\hline French & 20 & 10 & 10 \\
\hline
\end{tabular}

$.01]$ as well as for the French group $\left[F_{1}(1,10)=7.21\right.$, $\left.M S_{\mathrm{e}}=.01, p<.03 ; F_{2}(1,20)=5.51, M S_{\mathrm{e}}=.02, p<.03\right]$.

Although the English group recalled about 3\% more of the nontarget words of the sentences, the overall recall performance of the French group was better than that of the subjects in any of the three most comparable experiments of P\&L (Experiments 1, 3,6). Therefore, there is hardly any reason to believe that it was not the same kind of short-term sentence memory as in P\&L that was tapped in this experiment. Moreover, the less than $1 \%$ difference in spontaneous intrusion rate between language groups warrants a comparison of the lure intrusion effect in the two cases.

\section{Discussion}

This experiment shows that even though the English lure and French lure were not cognates, encountering the French lure in the distractor task still increased the probability of recalling the sentence with the target replaced with the French lure's English translation equivalent. However, although the interaction between lure presence and language did not remotely approach significance, it was nevertheless the case that the lure intrusion effect was slightly larger for the English group than for the French group. This tendency might be taken as an indication of a small, language-specific (and hence lexical) contribution to the lure intrusion effect.

In terms of our original hypothesis, Experiment 1 could be taken to show that close translation equivalents have strongly interconnected lexical representations, since the activation of the first-language (L1) representation is almost as large in response to the second-language (L2) translation equivalent as in response to the $\mathrm{L} 1$ word itself. Note that in the present experiment, such coactivation of L1 and L2 lexical entries must have been occurring unconsciously, and not as the product of a conscious translation strategy. Such a strategy would not have been relevant to the task and was made unlikely by the high presentation rate of the distractor words. In addition, no subjects in the French group, when debriefed, reported using a conscious translation strategy. But it is not unlikely that, for these subjects, subconscious "translation," in the sense of automatic coactivation of the $\mathrm{L} 1$ equivalent of an L2 word, might be part of the normal process of understanding L2 words (see, e.g., de Groot \& Nas, 1991; Williams, 1994). The locus of such translation activity may be in the strong L2-to-L1 lexical links in Kroll and Stewart's (1994) model of the bilingual lexicon.

As remarked in the introduction, however, in the course of running this experiment an alternative explanation of the cross-lingual lure intrusion effect suggested itself to us, one that does not depend upon lexical priming. The lure intrusion effect might reflect the distortion of the conceptual representation of the sentence through activation of the conceptual representation of the lure word.

For $\mathrm{P} \& \mathrm{~L}$, the primary function of the distractor task is that of activating lexical entries in the lexicon. Little attention is paid to the nature of the distractor task, as is 
shown by the fact that subjects' accuracy in the distractor task was reported only for Experiment 1 of Lombardi and Potter (1992), where it was 95\% (in our Experiment 1 it was $88 \%$ ). On the assumption that similar levels of performance were attained by the subjects in P\&L's experiments, it would seem that they were well able to remember the five words in the distractor list and compare them with the probe. Since the primary task was itself a memory task, it makes a lot of sense to ask how the memory for the five words affected the task of remembering the sentence. Given the obvious relevance of the lure to the conceptual content of the sentence, the representation that supported recall may have been a distorted conceptual representation that simply gave rise to the recall of the sentence with its target replaced with the lure. In other words, the lure intrusion effect could be primarily due not to the lexical entry of the lure's being more strongly activated/primed than that of the target, but to a distorted conceptual representation that the regenerative process relies on. If this were the case, Experiment 1 would not provide evidence relevant to the issue of bilingual lexical representation (apart from indicating that L1 and L2 words project onto the same conceptual representation). Instead it would provide evidence against a lexical priming account of the lure intrusion effect.

Two possible objections to this explanation of the lure intrusion effect will be considered immediately. First, in P\&L's Experiment 2, the lure intrusion effect was found even when the distractor list was presented before the sentence. However, this is hardly evidence against the conceptual distortion hypothesis, because in that experiment, subjects had to remember the five distractor words throughout the presentation of the sentence. Second, the slightly greater lure intrusion effect in the English condition of the present experiment may be taken to indicate that even if the conceptual distortion hypothesis is correct, there is still a component of the effect that is due to lexical priming. However, it is also possible that the French words in the word-matching task may have produced weaker activation of the corresponding concepts than was the case for English words (see Favreau \& Segalowitz, 1983 , for a demonstration that automatic semantic activation from $\mathrm{L} 2$ words is reduced even in highly proficient bilinguals). This would result in a lower likelihood of conceptual distortion. The hypothesis that the lure intrusion effect is not due in any part to lexical priming therefore remains tenable.

In Experiment 2, a different distractor task was used as an initial test of the viability of the conceptual distortion account of the lure intrusion effect. This time, the stimuli for the distractor task were pictures, and they were presented under conditions that were thought to minimize the probability that they would be covertly named. If the lure intrusion effect is caused by priming of lexical representations, it should disappear under these conditions, unless, that is, processing a picture automatically coactivates its name. If, on the other hand, the lure intrusion effect is due to conceptual distortion, it should still be obtained when lures are presented in pictorial form.

\section{EXPERIMENT 2}

It is difficult to design a distractor picture task that can be said with complete confidence to be comparable to the word-matching task used in P\&L's basic experimental paradigm. The ideal picture task must (1) be one that imposes, between sentence presentation and recall, more or less the same memory demands on subjects as does the word-matching task of P\&L's basic paradigm, (2) engage subjects in visual and conceptual processing of the pictures without unduly emphasizing the former (cf. P\&L's [p. 643] argument for ruling out the possibility of explaining the lure intrusion effect in terms of visual persistence of the distractor nouns), and (3) prevent subjects from naming the pictures. Two tasks were designed for use in two subexperiments (carried out on two separate groups of subjects).

\section{Experiment 2A}

In the first subexperiment, an object size categorization task was used, in which subjects were asked to judge whether the object denoted by a picture was in real life bigger than the computer monitor on which they saw the picture presented. The size categorization task was similar to that used by Hogaboam and Pellegrino (1978) and by Pellegrino, Rosinski, Chiesi, and Siegel (1977), and, as with other category-matching tasks on pictures, it is believed that in order to make their decisions subjects must activate the concepts of the pictures but they need not verbalize them (cf. Banks \& Flora, 1977; Carr, MacCauley, Sperber, \& Parmelee, 1982; Smith \& Magee, 1980). In this subexperiment, the size categorization task did not replace the word-matching distractor task of the basic paradigm; it was just a task inserted between sentence presentation and the original word-matching task which was followed by sentence recall. The reason for an addition rather than a replacement was that the size categorization task was not an explicit memory task, so the word-matching task had to be kept to maintain the same level of (explicit) memory demands as in the basic paradigm, and thereby the same level of sentence recall. The addition of the size categorization task would, like using a slower presentation rate for the French distractor nouns in Experiment 1, lengthen the time lag between sentence presentation and recall, the effect of which could be gauged, we suggest again, from the spontaneous intrusion rate and the overall recall rate.

\section{Method}

Subjects. The 16 subjects were undergraduates who had volunteered and were paid to participate. All were native speakers of English.

Materials. There were ten word pairs $\left(E_{t}-E_{1}\right)$, all derived from the triplets used in Experiment 1, for which a picture was available which it was known that subjects would readily and (almost) consensually name with $E_{\text {(for details of how the naming norms were }}$ established, see Wheeldon, 1989). In addition, for each pair, a set of five pictures and a set of five nouns were selected for use in the distractor tasks, with the constraint that the five nouns could not be the names of the five pictures and, almost as a corollary, the pictures 
and the nouns were conceptually unrelated to each other or to words in the sentence. The sentences were 10-17 words in length with a mean of 13 words, and they had all been used in Experiment 1. (See Appendix A.)

The 10 pairs were divided into two groups of 5 . Two experimental lists were formed by combining the respective sentences, distractor picture sets, and distractor noun sets of the pairs of one group with those of the pairs of the other group, counterbalancing for the group that was formed into the lure-present condition (i.e., for each word pair of the group in the lure-present condition, one of the five pictures in its distractor set was replaced with the picture of the appropriate $E_{l}$ ). Half the sentences in each experimental list were paired with picture sets with the pictures of $E_{1} S$ in them. The picture of $E_{1}$, when included, was never the first or the last picture in a distractor set.

In addition, there were 10 practice and filler sentences, for each of which a set of five pictures and a set of five nouns, chosen according to the same criteria as for those of the 10 pairs, were available.

Procedure. The sentences and the distractor words were presented using RSVP. Each trial began when subjects pressed the space bar. Three hash marks appeared for $300 \mathrm{msec}$ at the center of the screen, followed by a blank screen for $350 \mathrm{msec}$ and then the words of the sentence at a rate of five words per second. Immediately after the offset of the last word of the sentence, a row of three percentage signs appeared for $517 \mathrm{msec}$. Then the five distractor pictures were presented one after another; the subjects had been instructed to make a size categorization decision on each picture as it was presented by pressing one of two response keys on the keyboard. The pictures were followed by a row of three percentage signs for $517 \mathrm{msec}$, the distractor nouns presented with RSVP at a rate of four words per second, and then another row of three percentage signs. The capitalized probe word then appeared and stayed on the screen until the subjects had, using the same response keys as for the size categorization task, indicated their judgment of whether the probe word was one of the five distractor nouns just presented, after which the word RECALL appeared and the subjects recalled the sentence aloud as accurately as possible.

Before the subexperiment began, the subjects were given detailed instructions. Every subject received the same 5 practice trials followed by 15 pseudorandomly ordered trials (10 experimental and 5 filler trials). Five of the 15 trials had lure pictures included in the distractor picture sets, and such trials never appeared in succession. On half (of which three were the experimental trials that had lure pictures included in the distractor picture sets) of the 20 trials ( 5 practice +10 experimental +5 filler trials) that each subject received, the probe word was included in the distractor word set. The whole experimental session was audio recorded.

Design. The design was a 2 (lure presence) $\times 2$ (list assignment) factorial by subjects and by items, with the first factor varied within and the second between subjects and items, respectively. The main dependent variable was again the mean of percentage of errors of lure $\left(E_{1}\right)$ intrusion in sentence recall.

\section{Results}

Apart from the target words, $87 \%$ of the words of the sentences were recalled correctly. There were $15 \%$ errors, aside from lure intrusions, in recall of the target words and $9 \%$ errors in the word-matching distractor task.

The percentage of errors of lure intrusion in the two critical conditions is shown in Table 2. Analyses of variance revealed that the main effect of lure presence was significant by subjects $\left[F_{1}(1,14)=7.00, M S_{\mathrm{c}}=.03, p<\right.$ $.02]$ and marginally significant by items $\left[F_{2}(1,8)=4.80\right.$, $\left.M S_{\mathrm{e}}=.02, p=.06\right]$. Analyses of variance combining data from this subexperiment with data (on the triplets from
Table 2

Percentage of Errors of Lure Intrusion in Recall of Target

Words as a Function of Lure Presence in Experiment 2 and in the English Condition of Experiment 1

\begin{tabular}{cccc}
\hline & \multicolumn{2}{c}{$\begin{array}{c}\text { Presence of Lure } \\
\text { in the Distractor Set }\end{array}$} & $\begin{array}{c}\text { Lure Intrusion Effect } \\
\text { (Present-Absent) }\end{array}$ \\
\cline { 2 - 3 } Experiment & Present & Absent & \\
\hline 2A & 28 & 13 & 15 \\
2B & 19 & 9 & 10 \\
1 & 23 & 8 & 15 \\
\hline
\end{tabular}

Note-Experiment 2A, size categorization task on distractor pictures; Experiment 2B, picture-word matching task on distractor pictures. Experiment 1 , word-matching task on distractor words. The figures reported here for Experiment 1 are based on data on the triplets from which the word pairs used in Experiment 2 were derived and hence are slightly different from those reported in Table 1. Analyses of variance of the selected data of Experiment 1 yielded a significant effect of lure presence by subjects $\left[F_{1}(1,10)=4.96, M S_{\mathrm{e}}=.03, p=.05\right]$ and a marginally significant effect by items $\left[F_{2}(1,8)=5.03, M S_{\mathrm{e}}=.02, p=.055\right]$

which the word pairs of Experiment 2 were derived) from the English condition of Experiment 1 yielded a main effect of lure presence by subjects $\left[F_{1}(1,26)=12.32, M S_{\mathrm{e}}=\right.$ $.03, p<.01]$ and by items $\left[F_{2}(1,9)=10.57, M S_{\mathrm{e}}=.02\right.$, $p<.02]$, but no reliable main effect of experiment or interaction between experiment and lure presence (all $p \mathrm{~s}>.25$ )

\section{Experiment 2B}

In the second subexperiment, a picture-word matching task replaced the original word-matching task in P\&L's basic paradigm. Between sentence presentation and recall five pictures were presented using RSVP at the same rate at which distractor words were presented in the basic paradigm. They were followed by a capitalized probe word, and subjects had to decide whether the word was the name of any one of the five pictures they had just seen. This task, we believed, would impose a similar level of explicit memory demands as did the word-matching task, and with RSVP (four pictures per second), the pictures were presented too quickly to be named. It might be suggested that for the purpose of this experiment, probe pictures should have been used instead of probe words in order to eliminate the possibility of subjects' retrieving the pictures' names on seeing a probe word. Yet probing with pictures might have induced in subjects a taskdependent strategy of processing the distractor pictures only visually - that is, nonconceptually. With word probes and pictures presented with RSVP, the possibility was maximized of subjects' remembering the pictures in a conceptual format (see Intraub, 1981; Potter, 1976, 1993, for evidence of conceptual processing of rapidly presented pictures) and performing the matching task by comparing the conceptual representation of a probe word against the conceptual representations of the pictures.

\section{Method}

Subjects. The 16 subjects were undergraduates who had volunteered and were paid to participate. All were native speakers of English. 
Materials. The same 10 word pairs $\left(E_{t}-E_{1}\right)$ and associated sentences and distractor picture sets as for Experiment $2 \mathrm{~A}$ were used. Two presentation lists were formed in the same way as for the previous subexperiment (except that no distractor noun set was included). In addition, the same 10 practice and filler sentences and associated distractor picture sets were used. (See Appendix A.)

Procedure. The sentences and the distractor pictures were presented using RSVP. Each trial began when subjects pressed the space bar. Three hash marks appeared for $300 \mathrm{msec}$, followed by a blank screen for $350 \mathrm{msec}$ and then the words of the sentence at a rate of five words per second. Immediately after the offset of the last word of the sentence, a row of three percentage signs appeared for $517 \mathrm{msec}$, followed by the five distractor pictures presented at a rate of four pictures per second and then another row of three percentage signs for $250 \mathrm{msec}$. The capitalized probe word appeared and stayed on the screen until subjects had indicated their judgment, using the same response keys as for Experiment 2A, of whether the probe word was the name of any one of the five distractor pictures that they had just seen, after which the word RECALL appeared and the subjects recalled the sentence aloud as accurately as possible

Before this subexperiment began, the subjects were given detailed instructions. Every subject received the same 5 practice trials followed by 15 pseudorandomly ordered trials (10 experimental and 5 filler trials). Five of the 15 trials had lure pictures included in the distractor picture sets, and such trials never appeared in succession. On half (of which 3 were experimental trials that had lure pictures included in the distractor picture sets) of the 20 trials ( 5 practice +10 experimental +5 filler trials) that each subject received the probe word was the name of one of the five distractor pictures. The whole experimental session was audio recorded.

Design. The design was again a 2 (lure presence) $\times 2$ (list assignment) factorial by subjects and by items, with the first factor varied within and the second between subjects and items, respectively. The main dependent variable was again the mean of percentage of errors of lure $\left(E_{l}\right)$ intrusion in sentence recall.

\section{Results}

Apart from the target words, $87 \%$ of the words of the sentences were recalled correctly. There were $17 \%$ errors, aside from lure intrusions, in recall of the target words and $9 \%$ errors in the picture-word matching distractor task.

The percentage of errors of lure intrusion in the two critical conditions is shown in Table 2 . Analyses of variance revealed a main effect of lure presence by subjects $\left[F_{1}(1,14)=4.67, M S_{\mathrm{e}}=.02, p<.05\right]$ but not by items $\left[F_{2}(1,8)=1.31, M S_{\mathrm{e}}=.04\right]$. Analyses of variance combining data from this subexperiment with data (on the triplets from which the word pairs of Experiment 2 were derived) from the English condition of Experiment 1 again yielded a main effect of lure presence by subjects $\left[F_{1}(1,26)\right.$ $\left.=9.44, M S_{\mathrm{e}}=.02, p<.01\right]$ and by items $\left[F_{2}(1,9)=7.40\right.$, $\left.M S_{\mathrm{e}}=.02, p<.03\right]$, but no reliable main effect of experiment or interaction between experiment and lure presence (all $F \mathrm{~s}<1$ ).

\section{Discussion}

The results of the two subexperiments lend support to the conceptual distortion account of the lure intrusion effect. They show that although the distractor picture tasks called for, in all likelihood, conceptual but not verbal processing of the distractor pictures and hence did not result in any activation of lexical entries, subjects still tended to be more likely to recall an experimental sentence with the target replaced with the lure when a picture of the lure was in the distractor picture set. There are, however, two points about the data that merit more careful consideration.

First, compared with the results of Experiment 1, lower overall recall rates were found in Experiment 2 and a relatively high spontaneous intrusion rate was found in Experiment $2 \mathrm{~A}$, which may be attributed to the relatively longer lag between sentence presentation and recall in this subexperiment. But it should be noted that on both measures, the subjects in Experiment 2 did not perform any less well than those in the comparable experiments of P\&L and that at least in the by-subjects analyses, statistically significant lure intrusion effects of substantial magnitude were found in both subexperiments.

Second, the lure intrusion effect was numerically (but not statistically) smaller in Experiment 2B than in the comparable part of Experiment 1 . This replicates the trend observed in the overall analysis of Experiment 1-a slightly higher rate of intrusions was obtained when the lure was an English word than when it was either a French word or a picture. (This trend was not apparent in the comparison between Experiment $2 \mathrm{~A}$ and the comparable part of Experiment 1. However, the higher rate of spontaneous intrusions in Experiment 2A makes a direct comparison inappropriate.) Once again this might be taken as an indication of a specific lexical component of the lure intrusion effect in the English condition of Experiment 1 , such as lingering lexical activation of the lure. However, it is also possible that it reflects either a failure to identify the lure picture on some proportion of trials, or a context-dependent identification that diverged from that intended by the experimenters. Indeed, although the naming norms of the experimental pictures had been established (see Experiment 2A, Method, above), for some of the items it was possible that, given the content of a tobe-recalled sentence, the lure picture could have been identified as the target concept itself, thereby reinforcing the memory for the original sentence (e.g., our picture of a horse might have been identified as a pony, which was the target word). It is therefore not surprising that the size of the lure intrusion effect should have been slightly smaller when a picture distractor task was used.

The first two experiments provide suggestive but not conclusive evidence for the conceptual distortion account of the lure intrusion effect. However, the possibility remains that processing the pictures in the distractor tasks of Experiment 2 and processing French words in the word-matching task of Experiment 1 might have resulted in coactivation of corresponding English lexical representations (although it needs to be assumed that the activation of these representations is almost as strong in response to a picture or French word as it is in response to the English word itself). Given the difficulty of devising any distractor task in which lexical coactivation can definitely be ruled out, or in which the same degree of conceptual activation from the lure in the distractor task as in the standard paradigm can be guaranteed, in Experiment 3, we took a somewhat different approach. 
We addressed the question of whether it is possible in principle for the kind of lexical activation that results from a prior incidental encounter with a word during a wordmatching distractor task to influence the lexical access process in subsequent lexicalization of a semantically related concept.

\section{EXPERIMENT 3}

As pointed out in the general introduction, $P \& L$ 's theory explains a classic explanandum in memory research in terms of a relatively well-studied psycholinguistic process. A legitimate way to evaluate the theory is to assess whether it is compatible with our current understanding of the psycholinguistic process to which it appeals.

P\&L's lexical priming account of the lure intrusion effect requires that presentation of a word in the wordmatching task have a lasting adverse effect upon the process, at a later moment in time, of lexicalizing a concept from the sentence, by giving that word an advantage in its competition with other lexical items during sentence production (presumably by increasing its starting level of activation). We can therefore ask whether P\&L's lexical priming hypothesis is consistent with other findings concerning the effects of priming tasks upon the lexical access process in sentence production. To the best of our knowledge, there is no theory of the lexical access process in sentence production that is not empirically based on studies of the lexical access process in single-word production, most notably in picture naming. We therefore believe that we have to look at studies of picture naming and work on the widely accepted common assumption that the same lexical access process serves both normal sentence production and picture naming (Bock $\&$ Levelt, 1994), bearing in mind that according to $P \& L$, sentence recall involves the normal mechanisms of sentence production. ${ }^{2}$

Of particular relevance are the picture-naming studies that address the interfering effects on picture naming of a fairly recent prior encounter with a semantically related word (for a review of the voluminous literature on picture naming, see W. R. Glaser, 1992). ${ }^{3}$ The target picture is named correctly, but the response time is slowed because of competition from the prime word. Note that in contrast, in P\&L's paradigm the dependent measure is the frequency with which the target concept is named with the lure (= prime) word. This could be regarded as an extreme form of interference, in which the activation of the competitor word is so great that it wins the competition in the lexicalization of the concept. According to our understanding of the rationale underlying P\&L's lexical priming hypothesis, studies in which interference effects on correct responses are measured should be tapping the same process of lexical competition as studies in which lure intrusion rates are measured. If anything, picture-naming latencies should be more sensitive to the degree of activation of the lure/prime word, because even if that word is not activated to such an extent that it wins the competition, it should still make determination of the correct response more difficult.

Consideration of the available studies suggests that whether a semantic priming effect on picture naming is facilitatory or virtually nonexistent (Bajo, 1988; Carr et al., 1982; W. R. Glaser \& Düngelhoff, 1984; Irwin \& Lupker, 1983; Kroll \& Stewart, 1994; La Heij, Dirkx, \& Kramer, 1990; McCauley, Parmelee, Sperber, \& Carr, 1980; Sperber, McCauley, Ragain, \& Weil, 1979) or inhibitory (Brown, 1981; M. O. Glaser \& W. R. Glaser, 1982; W. R. Glaser \& Düngelhoff, 1984; Kroll \& Stewart, 1994; La Heij et al., 1990; Schriefers, Meyer, \& Levelt, 1990; Wheeldon \& Monsell, 1994) depends on both the task that is performed on the prime and the interstimulus interval between prime and target. The generalization most relevant to our present purpose is that inhibitory semantic priming effects on picture naming were obtained at (estimated) primetarget intervals of 4-12 sec in experiments in which subjects were required to produce the competitor word, either in response to a definition (Wheeldon \& Monsell, 1994), or as a picture-naming response (Brown, 1981; Kroll \& Stewart, 1994). Now, P\&L's distractor task involved presenting the lure word for mere recognition (and short-term storage) at (estimated) delays of no less than $3 \mathrm{sec}$ before sentence recall was required. Thus, although the interval between lure presentation and sentence recall in P\&L's task is comparable to that at which prime words have been shown to produce inhibitory semantic competition effects on picture naming, the experiments differ in whether the subjects actually have to produce the prime/lure word. It is possible that without this requirement, the kind of lexical priming that is assumed to underlie inhibitory competition effects in picture naming and that is implied by P\&L's lexical priming account does not occur. ${ }^{4}$ In Experiment 3, we tested this hypothesis directly.

In this experiment we used picture naming as a means of probing inhibitory semantic competition effects during lexicalization. Although the procedure represents a radical departure from Experiments 1 and 2, we believe that the results are still relevant to the present discussion of short-term sentence recall. What is at issue is whether the lexical access process is subject to competition induced by different types of prior "priming" task. We have no reason to believe that the nature of the lexicalization process differs in relevant respects according to whether the task is picture naming or sentence regeneration/production from the conceptual level during short-term sentence recall (also bear in mind that as we have already pointed out above, it is a widely accepted assumption in psycholinguistics research that the same lexicalization mechanisms serve both normal sentence production [which $P \& L$ argue is involved in short-term sentence recall] and picture naming [Bock and Levelt, 1994]).

Our aim in Experiment 3 was to compare, while keeping constant the prime-target interstimulus interval, the inhibitory effect (if any) on subsequent picture naming of the word-matching task as a lexical priming task, with that of another lexical priming task known to have such 
an adverse effect, on the assumption that the two effects should have the same locus. The task that we chose for comparison with the word-matching task was the definition task used by Wheeldon and Monsell (1994). In their experiments, subjects alternated, from trial to trial, between responding to a written definition and naming a pictured object. The subjects were found to be inhibited in naming a picture with a target word (e.g., shark) when they had produced a (designated) competing word (e.g., whale) in response to a definition on an immediately preceding trial or two trials ago. In Experiment 3, we therefore tested whether naming a pictured object with a target word would be retarded by recent prior incidental encounter with a competing word in a word-matching task (i.e., the distractor task of the basic paradigm), just as it is so affected by recent prior production of a competing word in a definition task. We asked subjects to alternate either between performing the word-matching task and naming pictures or between responding to written definitions/ descriptions of single words and naming pictures.

The target-competitor pairs for the present experiment were normed by Wheeldon (1989) and overlapped to a great extent with those used by Wheeldon and Monsell (1994). It was not possible to adapt the materials from either Experiment 1 or Experiment 2 for use in Experiment 3 , given the difficulty of finding distinguishable pictures for both target and lure concepts.

\section{Method}

Subjects. The 36 subjects were undergraduates who had volunteered and were paid to participate. All were native speakers of English.

Materials. The experimental vocabulary consisted of 36 semantically related pairs of English nouns $\left(E_{c}-E_{t}\right)$. (A listing of the items appears in Appendix B.) Initial selection of the items was constrained by the requirements that (1) a picture was available which could be readily named with the target word $\mathrm{E}_{\mathrm{t}}$ by subjects, and (2) a definition/ description was available to which subjects could readily respond with the competitor word $\mathrm{E}_{\mathrm{c}}$ and in which structural characteristics of the object denoted by the word $\mathrm{E}_{\mathrm{c}}$ were not mentioned. All the $36 E_{c}-E_{t}$ pairs had high ratings for functional similarity (between 4.6 and 6.9 on a 7-point scale) ${ }^{5}$ Half of them had a structural similarity rating of more than $5.3(M=6.0)$ and were classified as structurally similar pairs. The other half had a structural similarity rating of less than $5(M=3.7)$ and were classified as structurally dissimilar pairs.

For each pair, a set of five nouns was constructed for use in the word-matching task with the constraint that the nouns should be similar in number of letters to $E_{c}$, but unrelated in meaning to each other or to $E_{c}$ or $E_{t}$. In addition, a set of three nouns was selected for use in the definition task with the constraint that they should be unrelated in meaning to each other or to $\mathrm{E}_{\mathrm{c}}$ or $\mathrm{E}_{\mathrm{t}}$ and a definition description could be written for each of the three nouns to which subjects would readily respond with the chosen noun.

The 36 word pairs were divided into two groups of 18 , such that the two groups each had 9 structurally similar and 9 structurally dissimilar pairs and were matched for similarity ratings.

Two experimental lists were formed for the word-matching task by combining the respective word-matching noun sets and pictures of the word pairs of one group with those of the other group, counterbalancing for the group that was formed into the competitor-present condition (i.e., for each word pair of the group in the competitorpresent condition, one of the five nouns in its word-matching noun set was replaced with the appropriate $E_{c}$ ). Half the pictures in each experimental list were therefore paired with noun sets with $E_{c} s$ in them. Following $P \& L, E_{c}$, when included, was never the first or the last word in a word-matching noun set.

Similarly, two experimental lists were formed for the definition task by combining the respective definition noun sets and pictures of the word pairs of one group with those of the other group, again counterbalancing for the group that was formed into the competitor-present condition (i.e., for each word pair of the group in the competitorpresent condition, one of the three nouns in its definition noun set was replaced with the appropriate $E_{c}$ ). Again, half the pictures in each experimental list were therefore paired with noun sets with $E_{c} s$ in them. Since a valid comparison could not be made between the word-matching and definition conditions unless the time lag between the competitor and the target picture was kept approximately equal in both conditions, the competitor, when included, was always the second word in a definition noun set. In other words, an intervening word would be produced in response to a definition between the productions of a competitor and its corresponding target. (Recall that Wheeldon \& Monsell [1994] demonstrated the inhibitory semantic competition effect when no intervening word was produced as well as when two intervening words were produced between the competitor and the target.)

In addition, there were 26 practice and filler pictures, for each of which a set of five nouns and another set of three nouns, chosen according to the same criteria as for those of the 36 word pairs, were available for use in the word-matching and definition tasks, respectively. For none of these filler items was there a relationship between any of the nouns in the word-matching or definition noun set and the target picture.

Procedure. In the word-matching condition, the word-matching noun sets were presented with RSVP, using the same presentation parameters as in (the English condition of) Experiment 1, Experiment $2 \mathrm{~A}$, and P\&L. Immediately after the subject responded to the probe word, a fixation sign in the form of three hash marks appeared for $500 \mathrm{msec}$. After a blank interval of $500 \mathrm{msec}$, a beep, which the subjects could not hear, was sent to a tape recorder that was connected with the computer on which the experiment was run, and a picture was presented which subjects had been instructed to name as quickly and as accurately as possible with the most obvious word. After naming a picture, subjects pressed the space bar to initiate the following trial.

In the definition condition, each trial began when the subjects pressed the space bar. Three percentage signs appeared for $517 \mathrm{msec}$ at the center of the screen, followed by the definitions of the three nouns that made up a definition noun set appearing at the same time on the screen. The three definitions were presented on three separate lines, and the subjects were instructed to respond with a single word to each of them in turn from top to bottom. The subjects pressed the space bar once after responding to all three definitions. Thereafter, a fixation mark and target picture were presented in the same way as in the word-matching condition.

Every subject received two experimental blocks separated by a 30-sec interval: In the first block, 5 practice trials were followed by 24 pseudorandomly ordered trials ( 8 experimental trials with the competitor present in the noun set, 8 with the competitor absent, and 8 filler trials); in the second block, 3 practice trials were followed by 30 pseudorandomly ordered trials ( 10 experimental trials with the competitor present, 10 with the competitor absent, and 10 filler trials). Experimental trials on which competitors were present in the noun sets never appeared in succession, and the order of pictures was constant for all subjects (irrespective of experimental list or preceding task).

For the word-matching task, positive and negative probe trials were formed by electing one of the five words in the noun set to act as the probe (sampling from the five positions with equal frequency) and by selecting a probe word that was not present in the noun set, 
respectively. In accordance with previous experiments, the probe was never the competitor word (or the word that appeared in its place in the competitor-absent condition). Positive and negative probes were evenly distributed over competitor-present, competitor-absent, and filler trials.

Design. Each of the four experimental lists was given to 9 subjects. The design was therefore a mixed factorial in which preceding task was a between-subjects (but within-items) factor, presentation list/item subgroup was a between-subjects/items factor, structural similarity was a within-subjects but between-items factor, and presence of $E_{c}$ (i.e., semantic priming) was a within-subjects/items factor. The main dependent variable was the mean of picture-naming latency, which was measured manually on a speech editor from the recordings made in the experimental sessions.

\section{Results and Discussion}

Naming latency data of the following three categories were excluded from analysis: (1) data from trials on which a target picture was not named with $E_{t} ;(2)$ data from trials on which a target picture was not named within $2 \mathrm{sec}$; (3) data from trials on which $E_{c}$ could not be successfully elicited. One structurally similar item had an error rate of .56 in one condition, so data (in all conditions) on this item was also discarded from further analysis. Mean naming latency and percentage of missing data points in each critical condition calculated from the remaining data are shown in Table 3. The main effect of preceding task was significant by items $\left[F_{2}(1,31)=22.96, M S_{\mathrm{e}}=8,385.56\right.$, $p<.001]$ and marginally significant by subjects $\left[F_{1}(1,32)\right.$ $\left.=3.12, M S_{\mathrm{e}}=58,774.11, p<.09\right]$. The main effect of competitor presence was significant by subjects $\left[F_{1}(1,32)\right.$ $\left.=5.68, M S_{\mathrm{e}}=2,796.99, p<.03\right]$ and marginally significant by items $\left[F_{2}(1,31)=3.38, M S_{\mathrm{e}}=5,404.61, p<\right.$ .08]. The main effect of structural similarity was marginally significant only by subjects $\left[F_{1}(1,32)=3.19, M S_{\mathrm{e}}=\right.$ $4,761.57, p<.09]$. Most importantly, the two-way interaction between preceding task and competitor presence was significant by subjects and by items $\left[F_{1}(1,32)=\right.$ $8.72, M S_{\mathrm{e}}=2,796.99, p<.01 ; F_{2}(1,31)=5.55, M S_{\mathrm{e}}=$
$4,831.62, p<.03]$. No other significant two- or threeway interaction was observed, except a marginally significant two-way interaction between preceding task and structural similarity in the by-subjects analysis $\left[F_{1}(1,32)=\right.$ $\left.3.26, M S_{\mathrm{e}}=4,761.57, p<.09\right]$.

Analyses of variance of the missing data rates (arcsine transformed) revealed a highly significant main effect of preceding task by subjects and by items and a marginally significant interaction between preceding task and structural similarity by items. Statistical details of these effects are not reported here because they can be easily accounted for by the fact that Criterion 3 for data exclusion could only apply to the (competitor-present trials of the) definition condition.

To perform a more informative analysis of the effects on missing data rates, Criterion 3 was abandoned so that the same two criteria for data exclusion applied to both task conditions. Analyses of variance of the missing data rates now still showed a main effect of preceding task $\left[F_{1}(1,32)=5.86, M S_{\mathrm{e}}=0.01, p<.03 ; F_{2}(1,31)=11.43\right.$, $\left.M S_{\mathrm{e}}=0.01, p<.01\right]$ and a significant interaction between preceding task and structural similarity $\left[F_{1}(1,32)=4.97\right.$, $M S_{\mathrm{e}}=0.01, p<.04 ; F_{2}(1,31)=11.43, M S_{\mathrm{e}}=0.01, p<$ .05]. No other two- or three-way interaction effect was found. Analyses of variance of the naming latency now showed an almost identical pattern of results as before in terms of significance level, except that the aforementioned marginally significant main effect of competitor presence was now lost. (Mean naming latency obtained after data have been reinstated from trials on which $E_{t}$ but not $E_{c}$ could be successfully elicited is also reported in Table 3.)

We shall not discuss the main effect of or any interaction involving the factor of structural similarity, because the structurally similar pairs and the structurally dissimilar pairs were categorized according to their structural similarity ratings but no attempt was made to match them on the functional similarity rating. Besides, the factor of

Table 3

Mean Naming Latency in Milliseconds and Mean Percentage of Missing Data Points as a Function of Task Preceding Picture Naming, Presence of Semantic Competitor $\left(E_{c}\right)$ in the Preceding Noun Set, and Structural Similarity in Experiment 3

\begin{tabular}{|c|c|c|c|c|c|c|c|c|c|c|}
\hline \multirow{3}{*}{$\begin{array}{l}\text { Word } \\
\text { Pairs }\end{array}$} & \multirow{3}{*}{$\begin{array}{l}\text { Task Preceding } \\
\text { Picture Naming }\end{array}$} & \multicolumn{8}{|c|}{$\begin{array}{l}\text { Presence of } E_{c} \text { in the } \\
\text { Preceding Noun Set }\end{array}$} & \multirow{3}{*}{$\begin{array}{c}\text { Semantic } \\
\text { Priming Effect } \\
\text { (Present- } \\
\text { Absent) }\end{array}$} \\
\hline & & \multicolumn{4}{|c|}{ Present } & \multicolumn{4}{|c|}{ Absent } & \\
\hline & & RT & Inc. & Out. & Mis. & RT & Inc. & Out. & Mis. & \\
\hline \multirow[t]{2}{*}{$\begin{array}{l}\text { Structurally } \\
\quad \text { similar }(n=17)\end{array}$} & $\begin{array}{l}\text { Word } \\
\text { matching }\end{array}$ & 1,163 & 3.2 & 3.2 & - & 1,164 & 3.2 & 0 & - & -1 \\
\hline & $\begin{array}{l}\text { Responding to } \\
\text { definitions }\end{array}$ & $\begin{array}{c}1,282 \\
(1,285)\end{array}$ & 1.3 & 3.9 & 6.5 & 1,230 & 3.8 & 2.6 & - & $52(55)$ \\
\hline \multirow[t]{2}{*}{$\begin{array}{l}\text { Structurally } \\
\quad \text { dissimilar }(n=18)\end{array}$} & $\begin{array}{l}\text { Word } \\
\text { matching }\end{array}$ & 1,201 & 1.2 & 0 & - & 1,210 & 2.5 & 0.6 & - & -9 \\
\hline & $\begin{array}{l}\text { Responding to } \\
\text { definitions }\end{array}$ & $\begin{array}{c}1,277 \\
(1,278)\end{array}$ & 0.6 & 7.4 & 3.7 & 1,235 & 1.9 & 8.6 & - & $42(43)$ \\
\hline
\end{tabular}

Note-Data points are missing if they are from (1) trials on which a target picture was not named with $E_{t}$, (2) trials on which a target picture was not named within $2 \mathrm{sec}$, or (3) trials on which $E_{c}$ could not be successfully elicited. Percentages of data points lost to these three categories are given as Inc. (Incorrect), Out. (Outlying), Mis. (Misprimed). In parentheses are the reaction times obtained when Criterion 3 for data exclusion has been suspended-that is, when data points have been reinstated from trials on which a misprimed but correct naming response was made. There were $8 \%$ errors in the word-matching task itself. 
structural similarity is not relevant to the argument that we are pursuing (see note 5).

We have no ready explanation of the main effect of preceding task, which we admit cannot be fully accounted for by the task $\times$ competitor presence interaction, but a few points can be raised in relation to it. In this experiment, picture naming was performed in a task-switching situation, where it alternated predictably with either word matching or responding to definitions. It has long been known that even a predictable task switch can incur a cost in performance in terms of response time and accuracy (see, e.g., Jersild, 1927; Rogers \& Monsell, 1995; Spector \& Biederman, 1976), so it is not surprising that overall naming latencies were longer in this experiment than in typical picture-naming experiments, in which task switching is not involved. The main effect of preceding task may well be a reflection of the relative ease of switching to picture naming from word matching and responding to definitions, in spite of equal predictabilities of both kinds of switching. However, task switching in itself cannot be used to explain why presenting a lure in a word-matching task affected sentence recall in P\&L's experiments but not picture naming in the present experiment, since both paradigms involve a task switch. There is no reason to suppose that switching from word matching to picture naming should selectively disrupt the effect of lexical priming in a way that switching from word matching to sentence recall (in P\&L), or from responding to definitions to naming pictures (in the present experiment), does not.

The unambiguous significant two-way interaction between preceding task and semantic competitor priming shows that naming a pictured object with a target word could be retarded by recent prior production of a competing word in response to a definition, but not by recent prior incidental encounter with the same word in a wordmatching task. This suggests that an incidental encounter with a semantic competitor in a word-matching task, unlike production of it in response to a definition, cannot enhance the availability of its lexical representation in such a way and/or to such an extent as to affect the time course of the subsequent lexicalization of a semantically related concept. This, in turn, casts serious doubt on P\&L's lexical priming account, which explains the lure intrusion effect in terms of the increased availability of the lure's lexical representation as a result of its occurrence in the word-matching task, bearing in mind that this chain of reasoning rests on the assumption that we make and that is widely accepted in psycholinguistics research: namely, that the same lexicalization mechanisms serve both normal sentence production (which $\mathrm{P} \& \mathrm{~L}$ argue is involved in short-term sentence recall) and picture naming (Bock \& Levelt, 1994).

Why should there be such a marked contrast between the priming effects of recognition and production tasks on picture naming? One possibility is that mere presentation of a word for recognition simply results in less, and therefore less enduring, activation of its lexical entry than does actually selecting that lexical entry as a response to a def- inition. However, the fact that words presented for recognition support substantial long-lag repetition priming effects on other word recognition tasks (see, e.g., Forbach, Stanners, \& Hochhaus, 1974; Monsell, 1985; Scarborough, Cortese, \& Scarborough, 1977) would count against this degree-of-activation-per-se idea.

Another possibility is that there are in fact two lexical priming mechanisms with different time courses underlying the different kinds of inhibitory semantic competition effects on word production reported in the literature. One type of priming could arise from activation of the lexical entry itself and would be produced by both recognition of words in a word-matching task and production of words in response to definitions. This type of priming is captured in P\&L's notion of "lexical priming," but pace P\&L, we reason that this type of priming, which would be the source of the picture-word interference effects obtained at short and zero stimulus onset asynchronies (e.g., W. R. Glaser \& Düngelhoff, 1984; see also M. O. Glaser and W. R. Glaser, 1982; La Heij et al., 1990; Schriefers et al., 1990), would not last more than $200 \mathrm{msec}$ or so in the absence of attentional maintenance. ${ }^{6}$ This means that given the fact that the prime-target interval used in Experiment 3 was substantially longer than $200 \mathrm{msec}$, this type of priming could not be responsible for the competition effect of the definition task on picture naming, but in a sense it accounted for the lack of any effect of the word-matching task on picture naming. The second type of priming, which we argue is not captured in P\&L's use of the term "lexical priming," has its locus in longer lasting changes to the direction-specific mapping between domains of representation (Vitkovitch \& Humphreys, 1991; Wheeldon \& Monsell, 1994). Only target tasks that involve repeating some portion of the direction-specific mapping performed on the priming trial would be influenced by the latter type of priming (e.g., traditional repetition priming experiments entail repetition of the direction-specific mapping processes involved in recognizing the form of a word in a particular modality; see, e.g., Monsell, 1985). In the present case, the relevant direction-specific mapping is that from the conceptual to the lexical level, which is shared by the definition priming task and the picture-naming target task, but which is not required in the word-matching task. The exercise of this direction-specific mapping during the definition priming task causes (relatively long-lasting) changes to it which are such that when a target picture is semantically similar to the concept lexicalized in the definition task, there would be a propensity to repeat the earlier mapping onto the prime word, thereby slowing down determination of the target picture-naming response. On the other hand, the word-matching task requires the directionspecific mapping from the visual feature to the letter to the lexical to the conceptual level (for models of visual word recognition, see, e.g., McClelland \& Rumelhart, 1981), but critically in the present discussion, it does not involve the mapping from the conceptual to the lexical level. This means that as far as the picture-naming task in the word-matching condition of Experiment 3 is con- 
cerned, no word's mapping from the conceptual to the lexical level was, as a result of its being encountered in the prior word-matching task, predisposed/primed to be repeated during the picture-naming task, and activation of the lexical entry itself that resulted from the word-matching task (i.e., the first type of lexical priming mentioned above) had dissipated by the time picture naming was called for. In other words, the finding that the wordmatching task had no inhibitory semantic priming effect on subsequent picture naming was due to the nature of the word-matching task itself - the performance of the word-matching task lasted substantially longer than $200 \mathrm{msec}$ and did not involve the mapping from the conceptual to the lexical level, so it caused no changes to the mapping to be used in subsequent lexical access in picture naming.

This analysis of what underlies inhibitory semantic competition effects on word production (in picture naming) and the assumption of a common lexical access process in sentence production/recall and picture naming lead us to argue that Experiment 3 provides relevant data against an account of the lure intrusion effect in the standard paradigm in terms of lexical priming (of either of the two types discussed above): The same word-matching task, which lasts substantially longer than $200 \mathrm{msec}$ and does not involve the mapping from the conceptual to the lexical level, is used in the standard paradigm and in Experiment 3 , so it stands to reason that if this task caused no changes to the mapping to be used in the lexical access process (in picture naming) that followed it in Experiment 3 , it cannot cause any changes to the mapping to be used in the lexical access process (in sentence production) that follows it in the standard paradigm either. Likewise, Experiment 3 also provides relevant data to dispel any worry that the lure intrusion effect in the French condition of Experiment 1 was due to the possibility that during the word-matching task in French, there might have been lexical coactivation via direct word links at the lexical level (e.g., Kroll \& Stewart, 1994): We do not deny the existence of such lexical links or of such lexical coactivation during the word-matching task in French, but like the word-matching task in Experiment 3, the word-matching task in French in Experiment 1 lasted substantially longer than $200 \mathrm{msec}$, and most importantly, even if there were cross-language lexical coactivation via direct word links at the lexical level, it still did not involve the mapping from the conceptual to the lexical level, so it still could not have caused any changes to the mapping to be used in the lexical access process (in sentence production) that followed it. If this line of reasoning is accepted, it is clear that the two lure intrusion effects reported in Experiment 1 could not be due to either type of lexical priming (bearing in mind that only the first type was originally intended by $\mathrm{P} \& \mathrm{~L}$ in their use of the term) and have to be accounted for by some process other than either type of lexical priming. And given the fact that lure intrusion in the standard paradigm is clearly meaning based (cf. P\&L's Experiment 3), an obvious candi- date for this alternative process is, as we have suggested, conceptual distortion.

Armed with this conclusion we have just drawn from the results of both Experiments 1 and 3, we can further dispel any worry that the lure intrusion effects in Experiment 2 might have been caused by covert naming of pictures. Our argument starts with two lines of reasoning. First, if, as we have just argued independently, conceptual distortion was responsible for the lure intrusion effects reported in Experiment 1, it should also have been operating when the distractor task involved pictures. This means that regardless of whether covert naming of pictures occurred in Experiment 2, the lure intrusion effects found there must have had a conceptual component. Second, if covert naming of pictures had occurred, the direction-specific mapping from the conceptual to the lexical level would have been used in Experiment 2, and the distractor task involving pictures would have been like the definition task in Experiment 3, in that they both lasted substantially longer than $200 \mathrm{msec}$ but they both involved the mapping from the conceptual to the lexical level. It stands to reason that if the definition task caused changes to the mapping to be used in the lexical access process (in picture naming) that followed it in Experiment 3 , the covert naming of pictures during the distractor picture tasks could also have caused changes to the mapping to be used in the lexical access process (in sentence production) that followed it in Experiment 2 . This means that if covert naming of pictures had occurred in Experiment 2, the lure intrusion effects found there must have had a component of lexical priming of the second type that we have discussed above (recall that the second type of lexical priming is, we argue, not captured in P\&L's use of the term). Putting these two lines of reasoning together, we arrive at the prediction that if covert naming of pictures had occurred when the distractor task involved pictures, the lure intrusion effects in Experiment 2 should have been bigger than in the standard paradigm because there would have been two sources of the effects, one conceptual and one lexical (of the second type only). However, this prediction was clearly not borne out; the effects that were obtained in Experiment 2 were, if anything, slightly smaller than those in the standard paradigm. It is therefore obvious that either or both of the two lines of reasoning that the wrong prediction builds on does or do not hold. Since we have already presented independent evidence and argument for the first line of reasoning, we believe that the problem lies in the second line of reasoning, in particular the premise about covert naming of pictures. We therefore conclude that covert naming of pictures did not occur in Experiment $2 .^{7}$

In sum, the overall pattern of results across the three experiments suggests that it is theoretically most parsimonious to explain the lure intrusion effects obtained in Experiments 1 and 2 in terms of just one process-namely, conceptual distortion - and that in no case did lexical priming (of either type discussed above) have an influence on lure intrusions. 


\section{GENERAL DISCUSSION}

The present experiments cast doubt on P\&L's explanation of the lure intrusion effect in terms of lexical priming (either in the sense of the term originally intended by $P \& L$ or in the additional sense that we have introduced above). We found that the effect could still be obtained in the (arguable) absence of lexical activation of the lurethat is, when the lure was presented in a different language from that of sentence presentation and recall (Experiment 1 ), and when the lure was presented as a picture (Experiment 2). In addition, Experiment 3 provided evidence that mere presentation of a word in a word-matching task of the type used in P\&L's experiments does not influence the process of subsequently lexicalizing a related concept. If lexical priming is rejected as the main process responsible for the lure intrusion effect, two questions arise. First, what is the main source of the lure intrusion effect? Second, why is short-term sentence recall verbatim?

\section{The Source of the Lure Intrusion Effect}

We have suggested that the lure intrusion effect might be thought of as a change in the conceptual representation of the sentence, rather than as a product of lexical priming. It has long been known that short- and long-term recall of word lists suffers interference from semantically similar material encountered between the learning of target material and recall ("retroactive interference"; see, e.g., Baddeley, 1966; McGeoch \& MacDonald, 1931). Subjects are simply confused about which items have occurred in the to-be-recalled list and which have been encountered elsewhere in the experiment. It is possible that the lure intrusion effect is a type of retroactive interference phenomenon operating at somewhat even shorter delays than in experiments in which retroactive interference has traditionally been demonstrated. On this view, the lure intrusion effect occurs at the stage of reconstructing from long-term memory a conceptual representation of the sentence. Given that, if anything, the lure concept is more plausible in the sentence than the original target concept, then, in the face of competition between these two alternatives, the lure concept would probably be preferred. Since this process is occurring entirely at the conceptual level, then whether the lure concept has originally been activated by an English word, a French word, or a picture would be irrelevant.

As an additional assumption, the conceptual distortion account of the lure intrusion effect requires that the conceptual representation of the lure be sufficiently precise to ensure that the lure word rather than the target is selected at the time of recall. If this were not the case, the lure intrusion effect would not have been obtained when the lure was presented as a French word or a picture. However, in explaining the lure intrusion effect through activation of highly specific conceptual representations, we might simply appear to be proposing a version of the lexical priming hypothesis that is pitched at the level of lexically specific conceptual representations (as in Collins
\& Loftus's [1975] semantic network model, and more recently in Bock and Levelt's [1994] and Roelofs's [1993] accounts of the lexical access component of the language production process). One might argue that the lure word intrudes into sentence recall because its conceptual representation is primed by the lure word/picture. However, through an analysis of what underlies the semantic competition effects on word production reported in the literature, we argue that Experiment 3 specifically rules out priming explanations of the lure intrusion effect (and the verbatimness of short-term sentence recall), whether they be pitched at a lexical or a conceptual level. The activation of representations by the lure (and by the sentence), be they lexical or conceptual, does not appear to persist long enough to influence a subsequent production task.

The obvious difference between Experiment 3 and the standard paradigm used by P\&L (and adapted in the present Experiments 1 and 2) is that in the former, the production task was picture naming, whereas in the latter experiments, it was sentence recall. As argued in the introduction to Experiment 3, from the point of view of the lexical priming hypothesis this difference is irrelevant. But, given the pattern of results obtained, we would argue instead that precisely the lack of a recall component in Experiment 3 is crucial. It is in the process of recall itself that representations are reactivated as part of an episodic memory trace. The lure intrusion effect reflects interference at the stage of retrieving a conceptual representation from long-term memory, not competition at the stage of lexical access after a conceptual representation has already been retrieved.

\section{Why Is Short-Term Sentence Recall Verbatim?}

If we reject the lexical priming hypothesis, how then are we to explain the verbatimness of short-term sentence recall? We see two possibilities. The first extrapolates from the explanation of the lure intrusion effect to an explanation of verbatimness (as does P\&L's lexical priming hypothesis). We include the second possibility in order to sound a note of caution in making such an extrapolation-just because the lure intrusion effect seems to reflect a regenerative process in recall does not necessarily mean that recall of the rest of the sentence is also achieved by pure regeneration. In particular, we point out that the lure intrusion effect does not rule out the possibility that surface level traces are also involved in recalling the rest of the sentence.

Precise conceptual representation of the sentence. If the lure intrusion effect reflects regeneration from a precise conceptual representation of the lure, the same could be true of the rest of the sentence. Verbatim recall might then be explained in terms of conceptual representations that are sufficiently precise to ensure the selection of the lexical items (and syntactic structures) that have occurred in the original sentence without the mechanism of lexical priming. The loss of verbatim memory over time scales longer than those in the present experiments would be due to a change in the precision of the 
conceptual representation itself, or, as in the present paradigm, to interference from other, similar, memory traces.

There is now a sizable literature in the field of language variation and sociolinguistics, which examines many cases of what has hitherto been assumed to be free variation in language (see, e.g., Hudson, 1980; cf. also Clark's [e.g., 1993] principle of contrast). It is not unimaginable that so-called free lexical (and syntactic) variation does carry semantic, pragmatic, social, stylistic, or discoursal meaning that is somehow mentally represented. The existence of such nuances in meaning encoded at the conceptual level might be a contributing factor to the verbatimness of short-term sentence recall. Indeed, such representations would also be able to support long-term verbatim memory for sentences, as Long (1994) argues is the case at least for recognition memory for sentences with different discourse styles. In this connection, it is interesting that in a study examining the strategies used by actors to remember scripts, Noice (1992) found that all of her informants stressed the importance of analyzing why a character would use those exact words at that precise moment in the unfolding plot of the play, rather than simply memorizing the words by rote. It is typically reported that during the performance "the words just seem to be there" (Noice, 1992, p. 425). Since lexical priming (of either type) clearly could not be operating in this situation, the suggestion is that the conceptual representation is sufficiently developed to select the correct words by using the normal mechanisms of language production. (See also Stein \& Bransford [1979] for an experimental demonstration of the effectiveness of precise elaborations in improving verbatim memory for sentences.)

Interaction between conceptual and surface memories. One problem with the preceding account is that there is evidence to suggest that conceptual representations of sentences may not by themselves always be precise enough to support verbatim recall. It is possible to find brain-damaged patients who have impaired shortterm phonological memory and yet good comprehension of syntactically complex sentences, implying that they can form precise lexical, syntactic, propositional, and situation model representations. However, such patients show very poor short-term sentence recall (Butterworth, Campbell, \& Howard, 1986; Friedrich, Martin, \& Kemper, 1985; Martin, 1993; Martin, Shelton, \& Yaffee, 1994). Significantly, their errors tend to be paraphrases of the original (e.g., patient E.A., studied by Martin [1993], when asked to immediately recall "After eating dinner, the man walked the dog" produced "After supper, the man took his dog for a walk"). If the conceptual-level representations of sentences were precise, then immediate verbatim sentence recall ought to be possible even when short-term phonological memory is impaired, provided that sentence comprehension can be shown to be essentially intact. The patient data therefore suggests that short-term phonological memory does play a role in verbatim recall in normal subjects. ${ }^{8}$ Short-term recall might be seen as a process of reconstructing a partially decayed surface representation so as to be consistent with the conceptual representation of the sentence while at the same time conforming to the general linguistic constraints imposed by the language (as captured by the notion of "redintegration"; see, e.g., Hulme, Maughan, \& Brown, 1991; Patterson, Graham, \& Hodges, 1994; Schweickert, 1993). The $\mathrm{P} \& \mathrm{~L}$ paradigm could be seen as a rare case wherein an inconsistency is introduced into the relationship between the remnants of the surface trace of the sentence and the (distorted) conceptual level representation of its content. To account for the lure intrusion effect, it is necessary to assume that under such circumstances, the conceptual level dominates, and that (incorrect) recall for that part of the sentence is achieved by pure regeneration (as the results of the present experiments suggest). On this view, the existence of the lure intrusion effect does not necessarily rule out the possibility that surface traces are involved in short-term recall of the rest of the sentence, for which verbatimness might be secured by an interaction between mutually supportive surface and conceptual traces.

In conclusion, the focus of this article has been on the role of lexical priming in short-term sentence recall, and we have argued that, while the lure intrusion effect found by $P \& L$ demonstrates that short-term sentence recall involves a process of regeneration from the conceptual level, it does not necessarily mean that the lure intrusion effect and the verbatimness of short-term recall under normal circumstances should be attributed to lexical priming. We have found that a large proportion of the lure intrusion effect cannot be explained in terms of lexical priming and has to be attributed to conceptual-level processes. Whether it can be proved that there is some additional component of the lure intrusion effect that can be unambiguously attributed to the lexical level remains an issue for turther research. In addition, we have also considered the implications of our alternative explanation of the lure intrusion effect for the issue of verbatimness of short-term sentence recall. Given the results of our experiments, conceptual precision is a strong candidate explanation. However, we have also pointed out that it is too early to rule out a role for surface level traces, although even on this view, and following P\&L, we would argue that regeneration from the conceptual level is of crucial importance in short-term sentence recall.

\section{REFERENCES}

BaChman, L. F., \& Palmer, A. (1989). The construct validation of selfratings of communicative language ability. Language Testing, 6, 14-29.

BADDELEY, A. D. (1966). Short-term memory for word sequences as a function of acoustic, semantic and formal similarity. Quarterly Jour nal of Experimental Psychology, 18, 362-365.

BAJo, M.-T. (1988). Semantic facilitation with pictures and words. Journal of Experimental Psychology: Learning. Memory, \& Cognition, 14, 579-589.

Banks, W. P., \& FloRA, J. (1977). Semantic and perceptual processes in symbolic comparisons. Journal of Experimental Psychology: Human Perception \& Performance, 3, 278-290.

Bock, J. K., \& LeVelt, W. J. M. (1994). Language production: Gram- 
matical encoding. In M. A. Gernsbacher (Ed.), Handbook of psycholinguistics (pp. 945-984). London: Academic Press.

Brown, A. S. (1981). Inhibition in cued retrieval. Journal of Experimental Psychology: Human Learning \& Memory, 7, 204-215.

Butterworth, B., CAMPBell, R., \& Howard, D. (1986). The uses of short-term memory: A case study. Quarterly Journal of Experimental Psychology, 38A, 705-737.

Carr, T. H., McCauley, C., Sperber, R. D., \& Parmelee, C. M. (1982). Words, pictures, and priming: On semantic activation, conscious identification, and the automaticity of information processing. Journal of Experimental Psychology: Human Perception \& Performance, 8, 757-777.

CHEN, H.-C., \& LEUnG, Y.-S. (1989). Patterns of lexical processing in a nonnative language. Journal of Experimental Psychology: Learning, Memory, \& Cognition, 15, 316-325.

Clark, E. (1993). The lexicon in acquisition. Cambridge: Cambridge University Press.

Collins, A. M., \& LofTus, E. F. (1975). A spreading-activation theory of semantic processing. Psychological Review, 82, 407-428.

DE Groot, A. M. B., \& NAS, G. L. J. (1991). Lexical representation of cognates and noncognates in compound bilinguals. Journal of Memory \& Language, 30, 90-123.

Favreau, M., \& Segalowitz, N. S. (1983). Automatic and controlled processes in the first- and second-language reading of fluent bilinguals. Memory \& Cognition, 11, 565-574.

Forbach, G. B., StanNers, R. F., \& HochHaus, L. (1974). Repetition and practice effects in a lexical decision task. Memory \& Cognition, 2, 337-339.

Friedrich, F., Martin, R. C., \& Kemper, S. (1985). Consequences of a phonological coding deficit on sentence processing. Cognitive Neumpsychology, 2, 385-412.

GLANZER, M., FisCHER, B., \& DoRFMAN, D. (1984). Short-term storage in reading. Joumal of Verbal Learning \& Verbal Behavior, 23, 467-486.

Glaser, M. O., \& Glaser, W. R. (1982). Time course analysis of the Stroop phenomenon. Journal of Experimental Psychology: Human Perception \& Performance, 8, 875-894.

GlaSER, W. R. (1992). Picture naming. Cognition, 42, 61-105.

GLASER, W. R., \& DÜNGELHOFF, F.-J. (1984). The time-course of pictureword interference. Journal of Experimental Psychology: Human Perception \& Performance, 10, 640-654.

Hogaboam, T. W., \& Pellegrino, J. W. (1978). Hunting for individual differences in cognitive processes: Verbal ability and semantic processing of pictures and words. Memory \& Cognition, 6, 189-193.

Hudson, R. A. (1980). Sociolinguistics. Cambridge: Cambridge University Press.

Hulme, C., Maughan, S., \& Brown, G. D. A. (1991). Memory for familiar and unfamiliar words: Evidence for a long-term-memory contribution to short-term-memory span. Journal of Memory \& Language, 30, 685-701.

INTRAUB, H. (1981). Rapid conceptual identification of sequentially presented pictures. Journal of Experimental Psychology: Human Perception \& Performance, 7, 604-610.

IRWIN, D. I., \& LUPKER, S. J. (1983). Semantic priming of pictures and words: A levels of processing approach. Journal of Verbal Learning \& Verbal Behavior, 22, 45-60.

JAKIMIK, J., \& GLENBERG, A. (1990). Verbal learning meets psycholinguistics: Modality effects in the comprehension of anaphora. Journal of Memory \& Language, 29, 582-590.

JERSILD, A. T. (1927). Mental set and shift. Archives of Psychology, 14(Whole No. 89).

Kroll, J. F., \& STEWART, E. (1994). Category interference in translation and picture naming: Evidence for asymmetric connections between bilingual memory representations. Journal of Memory \& Language, 33, 149-174.

La He iJ, W., Dirkx, J., \& Kramer, P. (1990). Categorical interference and associative priming in picture naming. British Journal of Psychology, 81, 511-525.

LEVELT, W. J. M. (1989). Speaking: From intention to articulation. Cambridge, MA: MIT Press.

Levelt, W. J. M., \& Kelter, S. (1982). Surface form and memory in question answering. Cognitive Psychology, 14, 78-106.
Lombardi, L., \& Potter, M. C. (1992). The regeneration of syntax in short term memory. Journal of Memory \& Language, 31, 713-733.

LONG, D. L. (1994). The effects of pragmatics and discourse style on recognition memory for sentences. Discourse Processes, 17, 213-234.

MACDONALD, J. L., BoCK, K., \& KelLY, M. H. (1993). Word and world order: Semantic, phonological, and metrical determinants of serial position. Cognitive Psychology, 25, 188-230.

MARTIN, R. C. (1993). Short-term memory and sentence processing: Evidence from neuropsychology. Memory \& Cognition, 21, 176-183.

Martin, R. C., Shelton, J. R., \& Yaffee, L. S. (1994). Language processing and working memory: Neuropsychological evidence for separate phonological and semantic capacities. Journal of Memory \& Language, 33, 83-111.

McCauley, C., Parmelee, C. M., Sperber, R. D., \& Carr, T. H. (1980). Early extraction of meaning from pictures and its relation to conscious identification. Journal of Experimental Psychology: Human Perception \& Performance, 6, 265-276.

McClelland, J. L., \& Rumelhart, D. E. (1981). An interactive activation model of context effects in letter perception: Part 1. An account of basic findings. Psychological Review, 88, 375-407.

MCGEOCh, J. A., \& MACDONALD, W. T. (1931). Meaningful relation and retroactive inhibition. American Journal of Psychology, 43, 579-588.

MONSELL, S. (1985). Repetition and the lexicon. In A. W. Ellis (Ed.), Progress in the psychology of language (Vol. 2, pp. 147-195). Hillsdale, NJ: Erlbaum.

Norce, H. (1992). Elaborative memory strategies. Applied Cognitive Psychology, 6, 417-427.

Patterson, K., Graham, N., \& Hodges, J. R. (1994). The impact of semantic memory loss on phonological representations. Journal of Cognitive Neuroscience, 6, 57-69.

Pellegrino, J. W., Rosinski, R. R., Chiesi, H. L., \& Siegel, A. (1977) Picture-word differences in decision latency: An analysis of single and dual memory models. Memory \& Cognition, 5, 383-396.

POTTER, M. C. (1976). Short-term conceptual memory for pictures Journal of Experimental Psychology: Human Learning \& Memory 2, 509-522.

PotTer, M. C. (1993). Very short-term conceptual memory. Memory \& Cognition, 21, 156-161.

Potter, M. C., \& Lombardi, L. (1990). Regeneration in the short-term recall of sentences. Journal of Memory \& Language, 29, 633-654.

RoELOFS, A. (1993). Testing a non-decompositional theory of lemma retrieval in speaking: Retrieval of verbs. Cognition, 47, 59-87.

Rogers, R. D., \& MONSELl, S. (1995). Costs of a predictable switch between simple cognitive tasks. Journal of Experimental Psychology. General, 124, 207.231.

Sánchez-Casas, R., Davis, C. W., \& García-Albea, J. E. (1992) Bilingual lexical processing: Exploring the cognate/non-cognate distinction. European Journal of Cognitive Psychology, 4, 293-310.

Scarborough, D. L., Cortese, C., \& Scarborough, H. (1977). Frequency and repetition effects in lexical memory. Journal of Experimental Psychology: Human Perception \& Performance, 7, 3-12.

SCHENKEIN, J. (1980). A taxonomy for repeating action sequences in natural conversation. In B. Butterworth (Ed.), Language production (Vol. 1, pp. 21-47). London: Academic Press.

SChriefers, H., Meyer, A. S., \& LeVelt, W. J. M. (1990). Exploring the time course of lexical access in language production: Picture-word interference studies. Journal of Memory \& Language, 29, 86-102.

SCHWEICKERT, R. (1993). A multinominal processing tree model for degradation and redintegration in immediate recall. Memory \& Cognition, 21, 168-175.

Smith, M.C., \& MAgeE, L. E. (1980). Tracing the time course of pictureword processing. Journal of Experimental Psychology: General, 109, 373-392.

Spector, A., \& Biederman, I. (1976). Mental set and mental shift revisited. American Journal of Psychology, 89, 669-679.

Sperber, R. D., McCauley, C., Ragain, R. D., \& Weil, C. M. (1979). Semantic priming effects on picture and word processing. Memory \& Cognition, 7, 339-345

STEIN, B. S., \& BRANSFORD, J. D. (1979). Constraints on effective elaboration: Effects of precision and subject generation. Journal of Verbal Learning \& Verhal Behavior, 18, 769-777. 
Stubss, M. (1983). Discourse analysis. Oxford: Basil Blackwell. VITKOVITCH, M., \& HuMPhREYS, G. W. (1991). Perseverant responding in speeded naming of pictures: It's in the links. Journal of Experimental Psychology: Learning, Memory, \& Cognition, 17, 664-680.

WHEELDON, L. R. (1989). Priming of spoken word production. Unpublished doctoral dissertation, University of Cambridge.

WheEldon, L. R., \& Monsell, S. (1994). Inhibition of spoken word production by priming a semantic competitor. Journal of Memory \& Language, 33, 332-356.

WiLliams, J. N. (1994). The relationship between word meanings in the first and second language: Evidence for a common, but restricted, semantic code. European Journal of Cognitive Psychology, 6, 195-220.

\section{NOTES}

1. We shall later (in the discussion of Experiment 3) refine the notion of "lexical priming." Before then, any reference to the term lexical priming should be taken in the sense intended by P\&L—-that is, priming of the entry in the mental lexicon.

2. One anonymous reviewer has cautioned us that unlike picture naming, sentence production/recall also involves a syntactic component. It should nevertheless not be overlooked that P\&L unambiguously locate the lure intrusion effect at the lexical access component in the sentence production/recall process. Moreover, there is now a consensus among psycholinguists that lexical access, in some sense, precedes syntactic encoding in sentence production, which is often said to be lexically driven (see, e.g., Bock \& Levelt, 1994; Levelt, 1989). And importantly for our present purpose, this view on lexically driven syntactic encoding in sentence production/recall is also endorsed by Lombardi and Potter (1992), who, in exploring the ramifications of P\&L's theory for the question of whether sentence recall is constrained by any memory trace of the surface structure of a to-be-recalled sentence, argue that the selection of a synonymous lure verb over a target verb in (the lexical access component of) the sentence production/recall process results in the subcategorization requirement of the selected lure verb determining the product of the syntactic encoding component (and overriding the surface structure of the original sentence).

3. Notice that the Stroop-like interference effect on picture naming of a simultaneously presented semantically related word is not a reasonable comparison for the present purpose, because the lexical priming which $\mathrm{P} \& \mathrm{~L}$ argue supports sentence recall results from prior presentation of the to-be-recalled sentence in the basic paradigm.

4. The well-documented observation (e.g., Levelt \& Kelter, 1982 Schenkein, 1980) that in conversation people have a tendency to repeat both the content and function words used by their interlocutor (which are therefore not produced but only heard) might be thought to count against this possibility. However, it should be pointed out that the observation of repeated lexis in natural conversation is relevant to our present concern only if it can be established that given a particular conversational situation and given the conceptual content that they want to express, speakers do have a certain degree of freedom in choice of content words, which can by no means be taken for granted (cf. Clark's [e.g., 1993] principle of contrast). Moreover, it should be noted that the observation of repeated lexis in conversation does not have to be given a lexical-level explanation in terms of language processing. Working with naturalistic data, Stubbs (1983), a discourse analyst, observes in a dialogue that the density of lexical repetition varies as a function of "conversational harmony" (p. 27). This suggests to us that in terms of language processing, both lexical repetition itself and the change in the density of lexical repetition in natural conversation may have a conceptuallevel cause (though they need not have the same cause).

5. For details of the notions of structural and functional similarity as used here, see Wheeldon (1989) and Wheeldon and Monsell (1994), whom we follow in using both structurally and functionally similar pairs and structurally dissimilar and functionally similar pairs. Their purpose was to address the occasional suggestion in the literature that picture naming does not involve the activation of a nonlinguistic conceptual representation, an issue not immediately relevant in the present discussion

6. The facilitatory effect of a word upon picture naming obtained by, among others, W. R. Glaser and Düngelhoff (1984), at longer delays (e.g., up to $4 \mathrm{sec}$ ) would have to be assumed to be due not to activation at the lexical level, but to more persistent spreading activation at the conceptual level (see a related suggestion by Wheeldon \& Monsell, 1994)

7. Essentially the same set of arguments can be used to dispel any suggestion that the lure intrusion effect obtained in the French condition of Experiment 1 was due to cross-language lexical coactivation, not via direct word links at the lexical level, but via conceptually mediated translation (see, e.g., Kroll \& Stewart's [1994] discussion of the difference between these two types of translation activity)

8. We are aware of Potter's (1993) objection to relating the patient data to the lure intrusion effect in this way. She raises the possibility that patient E.A. might have had a deficit not only in short-term phonological memory, but also in the mental lexicon. It can also be pointed out that sentence recall might have been more immediate in the study of the patient than in the standard paradigm. Because of these comparability problems and the difficulty in deciding what is the null hypothesis in this case, we believe that the issue about the involvement of surface memory is still very much open.

\section{APPENDIX A \\ Experimental Material for Experiment 1}

Items with an asterisk were also used for Experiment 2. The sentence (target word in italics) is followed by the English lure and its French translation equivalent in parentheses.

He looked up at the provocative advert while waiting for the underground. (poster, affiche)

Every year the country's most influential author was awarded a prize. (writer, écrivain)

*The man had to struggle to get his bag off the crowded train. (suitcase, valise)

They couldn't store wine in the basement because it kept flooding. (cellar, cave)

He gave up his chair so that the woman would not have to stand. (seat, siège)

The tramp had no coins so he could not buy anything for dinner that night. (money, argent)

By the time the dawn came the night watchman was exhausted. (morning, matin)

*A football came over the fence from the playing fields into her garden. (hedge, haie)

*The family went to a seaside resort and rented a flat overlooking a sandy beach. (house, maison)

*The autumn evening was chilly so the man put on his jacket before leaving for the concert. (coat, manteau)

The parents admitted to the counsellor that they often smacked their kids for misbehaving. (children, enfants)

*The kitten kept bringing dead birds and mice into the house. (cat, chat)

On his way home he enjoyed talking to the beautiful lady on the bus. (woman, femme)

She responded to his joke with a laugh even though it was not funny. (smile, sourire)

*The schoolgirls put on their mittens before going out to play in the snow. - (gloves, gants)

*The woman spent the afternoon riding her pony all over the countryside. (horse, cheval)

*The farmer was angry when the puppy started attacking his chickens. (dog, chien) 


\section{APPENDIX A (Continued)}

The woman went to the sales and bought a rug for the hall. (carpet, tapis)

*The little boy asked his mother to choose a good story from the library. (book, livre)

Jane took the casserole from the stove and served it to the visitors. (oven, four)

*The man took off his trainers before entering the mosque. (shoes, chaussures)

The pleasure boat steamed across the water toward the island. (lake, lac)

\section{APPENDIX B \\ Experimental Material for Experiment 3}

The definition/description of a competitor is followed by the competitor and its corresponding TARGET in parentheses.

\section{Structurally Similar Pairs}

An __ a day keeps the doctor away. (apple, PEAR)

Heavy footwear for walkers (boot, SHOE)

Adult male of domestic cattle (bull, cow)

Animal that travellers ride on in the desert (camel, HORSE)

Edam is a kind of Dutch _.... (cheese, BUTTER)

Delicious, hard, brown food made from cocoa beans (chocolate, SWEET)

Ticking time piece that stands on a cupboard (clock, WATCH)

Small dwelling in rural area with thatched roof (cottage, HOUSE)

Piece of clothing worn by woman which covers her body and part of her legs (dress, SKIRT)

Cunning animal with a bushy tail, hunted by the gentry (fox, DOG)

In the race the tortoise beat the _.. (hare, RABBIT)

Form of air transport used in mountain rescue (helicopter, AEROPLANE)

The Queen lives at Buckingham __. (palace, CASTLE)

Four and twenty blackbirds baked in a _... (pie, CAKE)

Small soft fruit with a stone, whose skin can be yellow or purple (plum, STRAWBERRY)

You cut the wool off a sheep with a pair of __. (shears, SCISSORS)

It rises in the east and sets in the west. (sun, STAR)

A child often sucks its __. (thumb, FINGER)

\section{Structurally Dissimilar Pairs}

Pair of straps that men use to hold up trousers (braces, BELT)

She waited for the double-decker__ for half an hour. (bus, TRAIN)

Piece of plastic with pointed teeth, used for combing your hair (comb, BRUSH)

Sensory organ for hearing (ear, EYE)

Cinderella had a __ godmother. (fairy, ANGEL)

Transparent utensil from which you drink liquid (glass, CUP)

Spherical representation of surface features of the Earth (globe, MAP)

Warm covering you wear on your hand (glove, SOCK)

They were given a twenty-one _ salute. (gun, CANNON)

Small portable mechanical device used for igniting cigarettes (lighter, MATCH)

A man who lives in a monastery (monk, NUN)

You put food into your _ when you eat. (mouth, NOSE)

Wooden implement for smoking tobacco (pipe, CIGARETTE)

Long strip of material worn round neck for warmth (scarf, TIE)

Public place where children are educated (school, $\mathrm{CHURCH}$ )

Part of skeleton, corresponding to the head (skull, BONE)

It falls in white fluffy flakes from the sky. (snow, RAIN)

You switch it on to watch programmes. (television, RADIO) 